\title{
ESCOLA ÚNICA E EDUCAÇÃO RURAL NO ESTADO NOVO EM PORTUGAL
}

\section{Unique School and Rural Education in the New State in Portugal}

\section{Escuela Única y educación rural bajo el Estado Novo en Portugal}

\section{Justino Magalhães*}

Data de recepção: 30/03/2017 • Data de aceitação: 30/08/2017

Resumo. A Escola Única Portuguesa não estabeleceu com a cultura e a sociedade uma relação qualitativamente uniforme. O educacional escolar frequentemente apresentou um contraste entre o mundo rural, tomado como idílico, e o mundo urbano apresentado como ameaçador para a moral e o bem-estar dos indivíduos. Correlativamente, o currículo escolar foi aberto ao progresso e ao cosmopolitismo. A cultura rural, o universo material e o campo simbólico do Portugal rural eram negligenciados e tomados como arcaicos. Esta indeterminação e aquele paradoxo radicavam em pressupostos ideológicas e nacionalistas, e encontraram consequência na norma escolar e no corporativismo do Estado Novo. A portugalidade subjacente à Escola Única não foi necessariamente rural, mas o minimalismo literácito facultado pela alfabetização escolar afigurou-se como compatível com a ruralidade. Proponho-me documentar e problematizar este assunto. Referir-me-ei também às políticas de ampliação da rede escolar e de formação de professores. Trarei por fim à colação o Inquérito internacional promovido pela UNESCO, Possibilités d'Accès à l'Éducation dans les Zones Rurales (1958), em resposta ao qual o Estado Português exarou a lacónica resposta "aucune différence», deixando antever, deste modo, as virtualidades da escola única portuguesa.

Palavras-chave: Educação popular; Escola Única; Educação rural; Estado Novo.

Abstract. The Unique Portuguese School did not establish a qualitatively uniform relationship with culture and society. The issue of education often presented a contrast between the rural world, taken as idyllic, and the urban world,

\footnotetext{
* Instituto de Educação da Universidade de Lisboa. Alameda da Universidade 1649-013, Lisboa, Portugal.justinomagalhaes@ie.ulisboa.pt
} 
presented as threatening to the morale and well-being of individuals. Correlatively, the school curriculum showed an openness to progress and cosmopolitanism. Rural culture, the material universe, and the symbolic countryside of rural Portugal were neglected and seen as being archaic. This indeterminacy and that paradox were based on ideological and nationalistic assumptions, and had their consequences in school norms and in the corporatism of the Estado Novo. The portugality underlying the Unique School would not necessarily be rural, but the minimalist formation provided by school literacy seemed compatible with rurality. I propose to document and problematize this subject. I will also refer to policies for expanding the school network and teacher training. I will conclude by examining the International Survey promoted by the UNESCO, Possibilités d'Accès à l'Éducation dans les Zones Rurales (1958), in response to which the Portuguese State has issued the laconic answer "aucune difference». This would seem to show the possibilities of the Portuguese unique school.

Keywords: Popular education; Unique School; Rural education; new state

Resumen. La Escuela Única Portuguesa no estableció una relación cualitativamente uniforme con la cultura y la sociedad. La cuestión escolar frecuentemente presentó un contraste entre el mundo rural, considerado idílico, y el mundo urbano presentado como amenazador para la moral y el bienestar de los individuos. Correlativamente, el currículum escolar se abrió al progreso y al cosmopolitismo. La cultura rural, el universo material y el campo simbólico del Portugal rural eran desconsiderados y tomados como arcaicos. Esta indeterminación y aquella paradoja se asentaban en presupuestos ideológicos y nacionalistas, con consecuencias en la norma escolar y en el corporativismo del Estado Novo. La portugalidad subyacente a la Escuela Única no fue necesariamente rural, pero el minimalismo formativo facultado por la alfabetización escolar se sintió compatible con la ruralidad. Me propongo documentar y problematizar este asunto. Me referiré también a las políticas de ampliación de la red escolar y de formación de profesores. Traeré por fin a colación el Interrogatorio internacional promovido por la UNESCO, Possibilités d'Accès a la l'Éducation dans les Zones Rurales (1958), en respuesta al cual el Estado Portugués indicó lacónicamente aucune différence, dejando entrever, de este modo, las virtualidades de la escuela única portuguesa.

Palabras clave: Educación popular; Escuela Única; Educación rural; Estado Novo. 


\section{INTRODUÇÃO}

Escola Única e Educação Rural constituem um tema que é também um problema. A Escola Única foi a modalidade implantada a partir da Europa das Luzes como modalidade de ensino correspondente à instrução elementar. Assegurava a formação e a comunicação em língua materna, proporcionando habilitações básicas de ler e escrever, uma iniciação cívica, uma integração patriótica. Com as Revoluções Liberais, a escola elementar tornou-se universal e progressivamente obrigatória. A Escola Única era factor de justiça social, possibilitando a igualdade de percursos curriculares e a paridade de certificações. Era normativa e normalizada. Estatalizada, nacionalizada, regimentada, tornou-se a principal representação de Escola Pública.

O avanço da industrialização e da urbanização consolidou uma cultura e uma prática escolares que tomavam o mundo e a cultura rural como arcaicos, ainda que necessários e convenientes em termos económicos, sociais, laborais. A agricultura era actividade económica primária. Em Portugal, nas últimas décadas de Oitocentos, o ensino agrícola era uma modalidade de complemento escolar e de profissionalização. A Primeira República desdobrou a oferta escolar para o mundo rural, através de Escolas Móveis que asseguravam a alfabetização. Na Ditadura Militar, as Escolas Móveis foram substituídas por escolas incompletas e no Estado Novo por Postos Escolares. Por princípio, a noção de escolas incompletas satisfaz uma parte da Escola Única. Continuou todavia polémica a relação entre Escolas Novas e Escola Única, por parte de pedagogos, pedagogistas, políticos. O Projecto de Lei Camoesas, apresentado ao Parlamento em 1923, sustentava a modalidade da Escola Única, progressiva. Também as diversas experiências de Escola Nova consignaram planos pedagógico-didácticos diferenciados, mas não uma instituição escolar alternativa.

O Estado Novo consignou a Escola Única Elementar, mas manteve duas vias para o ensino de continuidade: o ensino técnico-profissional e o ensino liceal. Uma parte significativa dos alunos que concluíam a instrução primária entrava directamente no mundo profissional. Foi já na década de 50 que a pressão de novos públicos escolarizados (que desejavam prosseguir os estudos liceais) e a conveniência de prolongar a escolarização para uma melhor formação técnica forçaram a revisão da 
estrutura escolar e a criação de um ciclo com valências comuns. Conclui António Nóvoa que «a tradicional recusa nacionalista da escola única dá lugar a novas orientações, no quadro de uma inevitável reformulação do projecto escolar». ${ }^{1}$

Para as populações rurais portuguesas tardou a ser oferecido um ensino correspondente à escolarização elementar e não houve uma oferta escolar específica para o mundo rural. Este artigo procura apresentar aquele processo e mostrar que a noção de Escola Única nem foi pacífica como ideário, nem suficiente como Escola Pública; assenta na tese de que o mundo rural esteve presente nas decisões políticas e pedagógicas, mas não foi assumido como merecendo uma escolarização específica, orientada para um desenvolvimento endógeno, nem adequada por forma a garantir uma igualdade de resultados. As maiores taxas de absentismo e de incumprimento escolar eram fundamentalmente geradas no mundo rural. Mas no plano mais amplo, interrogar a escola rural é necessariamente problematizar a Educação Rural. Retomo aqui de modo ampliado e fundamentado, as ideias que sobre este assunto consignei em trabalhos anteriores. $^{2}$

A nível macro-económico, o modelo de desenvolvimento ocidental caracterizou-se pela secundarização do sector primário, em contraste com o fomento dos sectores secundário e terciário. Foi só por meados do século XX, sacrificada a humanidade a duas guerras mundiais e implantada a UNESCO como entidade transnacional para a igualdade de direitos e para um desenvolvimento orientado para o bem-estar individual e social, que a Educação Rural se tornou tema pedagógico e objecto curricular, reconhecido nas especificidades e desafiando a unicidade do modelo escolar. As orientações políticas e institucionais, favoráveis à modalidade das comprehensive schools, careciam de intervenções pedagógicas qualitativas e discriminadas nos planos mesológico e etnocultural. Os planos de Desenvolvimento do Mediterrâneo, envolvendo Espanha, Portugal, Itália, Grécia, Roménia — países onde as desigualdades sociais entre o

\footnotetext{
${ }^{1}$ António Nóvoa, «A “Educação Nacional” », en Portugal e o Estado Novo (1930-1960), [Nova História de Portugal - vol. XII], coord. Fernando Rosas (Lisboa: Editorial Presença,1992), 489.

2 Justino Magalhães. Da Cadeira ao Banco. Escola e Modernização (séculos XVIII-XX) (Lisboa: Educa, 2010); Justino Magalhães, «O Rural e a Escolarização em Portugal». Educação e Filosofia. Uberlândia, 27, n. especial (2013), 63-73.

http://dx.doi.org/10.14393/REVEDFIL.issn.0102-6801.v27nEspeciala2013-p63a74
} 
rural e o urbano se mantinham acentuadas com repercussão nos índices de escolarização- fizeram parte dessa caracterização e dessa acção. No plano interno, tanto em Espanha como em Portugal, na década de 60, foram implementados programas de intervenção tendentes à melhoria da qualidade de vida e à promoção das populações rurais. Em Portugal, foi criada a figura do Agente de Desenvolvimento Rural, que actuaria junto dos distintos interlocutores a nível local.

\section{ESCOLA ÚNICA E ESCOLA PÚBLICA}

A problemática da Educação Rural está associada à da Escola Única e necessariamente também à da Escola Pública. A cronologia dos grandes debates sobre a escola apresenta algumas sobreposições; todavia, a história da educação rural revela aspectos específicos. Desde Jean Amós Coménio que a noção de escola contém uma perspectiva de unicidade e de abrangência, no pressuposto de que daí resultavam simultaneamente benefícios para os indivíduos e vantagens colectivas. A uniformidade da oferta educativa estava subjacente ao Iluminismo e à estatalização da escola, no quadro dos Estados-Nações de final do Antigo Regime. Estava igualmente subjacente à noção de Escolas Normais e de Normalistas, estabelecida em França na sequência dos acontecimentos revolucionários de 1789. A uniformidade curricular legitimava a obrigatoriedade de inscrição e o controlo de frequência.

A escola moderna deu curso à cultura escrita e prefigurou um currículo orientado para a noção de homem letrado. O processo escolar constituía uma tecnologia do social, caracterizada pela segmentação curricular e por diferentes perspectivas formativas. Comportava, no entanto, distinção no acesso e no grau de consecução.

Para Portugal, tomando como referência o Plano de Estudos constante do Alvará Régio de 6 de Novembro de 1772, observa-se que a progressão dos estudos configurava o perfil do letrado. Dando curso ao Iluminismo pombalino, o Alvará principiava pela denúncia de que os Mestres das Escolas Menores haviam dispersado os alunos. Continha a organização e a implementação do Plano das Escolas Menores, nomeadamente: criação de escolas, concurso e exame dos professores, matérias, regras para o exercício de funções docentes como mestre régio ou mestre particular, 
público escolarizável, condições de acesso, aproveitamento dos alunos. Do referido Alvará, constavam os principais critérios para criação de Escolas Menores e a noção de um currículo letrado vertical até à Universidade.

Na base do Plano Iluminado, constante do referido Alvará, estavam os indivíduos e os segmentos sociais que eram «necessariamente empregados nos serviços rústicos, e nas Artes Fabris, que ministra[va]m o sustento aos Povos, e constitu[ía)m os braços, e mãos do Corpo Político». Tais segmentos ficavam confiados ao cuidado dos agentes tradicionais de educação, devendo ser capacitados com as «instruções dos párocos» - revistas em conformidade com as novas orientações políticas e ideológicas de amos e patrões. De entre os sectores envolvidos pelo Plano Régio dos Estudos, uns ficar-se-iam pelos exercícios de ler, escrever e contar; outros prosseguiam pelo estudo da Língua Latina. Ficaria habilitado para a «Filologia o menor número dos outros Mancebos, que aspira[va]m às aplicações daquelas Faculdades Académicas, que fazem figurar os Homens nos Estados».

A perspectiva uniforme e gradual foi retomada na segunda metade do século XIX, quando, na Alemanha como em França, o argumento principal era o de que a Escola Única deveria ser nacional, suportada pelo Estado, cívica e laica. Esses mesmos princípios estavam na base da expansão do modelo da Escola Única a outros países europeus, nomeadamente a Espanha e Portugal. Não era, no entanto, um movimento uniforme, nem convergente. Havia argumentos de natureza cultural, pedagógica, política, que favoreciam a uniformidade, mas relativamente a esses mesmos campos havia também outros pensadores e pedagogos que salientavam a diferenciação e a especificidade.

Em Portugal, a Regeneração (que assinalou as últimas décadas do século XIX) introduziu a noção de Educação Popular, como movimento abrangente de alfabetização e leitura, transversal aos mundos urbano e rural. Este movimento abrangente de aculturação escrita, combinando alfabetização, patriotismo e elementos de formação cívica, preparou um currículo elementar mínimo, que veio a ser lecionado em campanhas de alfabetização e posteriormente através de Escolas Móveis. 
A aplicação do atributo popular quer à educação quer às bibliotecas públicas estabelecia o contraste com o erudito e traduzia a diferença face à educação liberal e à formação humanística. Tal como sucedia noutros países europeus, também em Portugal a educação popular era parte da escola única, nacional. Assim sucedeu, na sequência das políticas de Regeneração do último quartel de Oitocentos. Assim sucedeu também com o Plano de Educação Popular, lançado em 1953, no âmbito da Campanha Nacional de Educação de Adultos e instituído pelo Decreto-Lei n. ${ }^{\circ} 38968$ e pelo Decreto n. ${ }^{\circ} 38969$ de 27 de Outubro de 1952. Foi nesse contexto que, comentando a melhoria dos quantitativos de matrícula no ensino primário oficial e particular, no período compreendido entre 1952 e 1955 (em que vigorou a primeira fase da Campanha Nacional de Educação de Adultos), o Subsecretário de Estado da Educação Nacional não deixou de acumular os dados referentes à matrícula de menores com os da matrícula de adultos, perfazendo o total de 1.018 .958 para o ensino oficial. ${ }^{3}$ Acresce a esta perspectiva a relevância atribuída aos professores para integrarem, a nível local, as diferentes vias de aculturação escrita.

Na Alemanha, o movimento da Escola Única assumiu contornos institucionais. Em 1848, uma associação de professores, em Eisenach, lançou o pedido de "criação de uma escola alemã» organizada de forma progressiva e unitária. Na sequência da Guerra Franco-Alemã (1870-1871), o desígnio de uma escola nacional foi tornado prioritário nos dois países. Kerschensteiner impulsionou a criação de uma escola única, com base no trabalho. A Constituição da República de Weimar, implantada em 1918, instituiu as bases e consignou a Escola Única na Alemanha. Nos termos do Art. $^{\circ} 146^{\circ}$ da Constituição de 1919 , fora determinada a 'escola unificada' na Alemanha, nos seguintes termos:

A instrução pública constituir-se-á organicamente. O ensino médio e superior assentarão numa escola básica comum a todos. Nessa organização será levada em conta a multiplicidade de profissões da vida; e para a admissão de uma criança em determinada escola só se considerarão a sua capacidade e vocação e, não,

\footnotetext{
${ }^{3}$ Cf. Plano de Educação Popular XVI, Série A, N. ${ }^{\circ}$ 11, Na Segunda Fase do Plano de Educação Popular. Discursos proferidos por SS. Exas o Ministro e o Subsecretário de Estado da Educação Nacional, na reunião das Comissões Centrais e da Comissão Distrital de Lisboa da Campanha Nacional de Educação de Adultos, em 3 de Dezembro de 1955 (Lisboa: Campanha Nacional de Educação de Adultos, 1955), 26.
} 
a posição social ou económica, nem a confissão religiosa dos pais. $^{4}$

À luz da Constituição da República de Weimar, a Escola Única era compatível com a liberdade confessional (Art. ${ }^{\circ}$ n. ${ }^{\circ} 149$ ).

Os mesmos princípios de igualdade de tratamento, com vista a uma aristocracia da inteligência, foram assumidos em França, nomeadamente na reconstrução subsequente à I Guerra Mundial. O decreto de De Mouzie, publicado em Setembro de 1925, unificava os programas e normalizava o professorado, incluindo o das escolas primárias e o das escolas preparatórias dos liceus; o princípio da Escola Única foi extensivo ao ensino secundário, tornado gratuito a partir de 1930. Para Espanha, Lorenzo Luzuriaga apontou a Institución Libre de Enseñanza como modelo pedagógico de unidade entre o jardim-de-infância e os graus superiores de ensino. Implantada a República, a Constituição espanhola de 1931 estipulava, no Art. $^{\circ} 48 .^{\circ}$, a instauração da escola unificada, confiada ao Estado.

\section{ESCOLA ÚNICA E EDUCAÇÃO INTEGRAL EM PORTUGAL}

Em Portugal, após a implantação da República, a escola cumpriu o principal objectivo de promover uma educação republicana e as noções de escola única e educação integral tenderam a sobrepor-se. Tal desígnio comportou pedagogias diferenciadas, por graus de ensino e por segmentos socioprodutivos. Nos termos do Decreto de 26 de Maio de 1911 que organizava o ensino agrícola, o ensino primário rural visava fornecer aos indivíduos que não tinham frequentado a instrução elementar noções aplicadas às artes agrícolas e conhecimentos que favorecessem um espírito voltado para a agricultura. A temática foi retomada na base III da lei n. ${ }^{\circ} 824$, com data de 8 de Setembro de 1917, que admitia a criação de escolas primárias rurais que ministrassem o ensino primário e iniciassem à profissão agrícola. A idade mínima para admissão era de sete anos. Tais ensejos foram contudo de reduzido impacto e não constituíram um movimento organizado.

\footnotetext{
${ }^{4}$ Apud Casimiro Manuel Martins Amado, O Debate acerca da Escola Única, na Imprensa Portuguesa (Évora: Universidade de Évora, 1991), 56.
} 
Leonardo Coimbra (que foi ministro da instrução, em 1919 e, de novo, entre novembro de 1923 e Janeiro de 1924) defendia que o ensino assegurasse um mínimo de instrução a todos e um máximo aos mais capazes, independentemente da origem. ${ }^{5}$ Caberia ao ensino primário superior assegurar um ensino vocacional.

António Sérgio, ministro da Instrução (1923-1924), propunha que a escola fosse integrada no meio através de uma educação pelo trabalho - a Escola Única pelo Trabalho. Escrevendo em 1953 em defesa de uma economia cooperativa assente na autonomia económica, António Sérgio referia que nada do que escrevera desde 1911 em matéria de pedagogia escolar tinha sido respeitado, e reincidia numa pedagogia escolar com base na autonomia cívica dos escolares, influenciada «pela vida civil, dos nossos concelhos antigos, dos nossos municípios modernos, e na organização democrática das cooperativas de hoje». ${ }^{6}$ Propunha a criação de uma Junta das Escolas Experimentais, que cultivassem a autonomia dos alunos, tal como sucedia nos métodos de Dalton e de Winnetka. A escola daria curso à

educação para o trabalho, através do trabalho: e só como instrumento da educação para o trabalho se ensinariam as artes da leitura e da escrita, e de maneira alguma como fins em si. A leitura e a escrita, desligadas de uma autonómica educação no trabalho, feita na liberdade e para a liberdade, integradora dos jovens no seu ambiente rural, levam os rapazinhos a fugir dos campos. $^{7}$

Levando mais longe o plano de integração entre escola e desenvolvimento local e regional, António Sérgio propunha um regime de autonomia cívica. A autonomia deveria ser preparada nas escolas primárias. Para isso, «nos rincões rurais conviria que a actividade escolar primária tomasse como centro o lavrador como tal, a sua lida rústica, agregados

${ }^{5}$ Cf. Marques Teixeira [Manuel Marques Teixeira de Oliveira], Leonardo Coimbra e a Escola Única (Porto: Edições Marânus, 1961), 46.

${ }^{6}$ António Sérgio, Obras Completas. Democracia. Diálogos de Doutrina Democrática. Alocução aos Socialistas. Cartas do Terceiro Homem (Lisboa: Livraria Sá da Costa Editora, 1974), 189.

${ }^{7}$ Sérgio, Obras Completas, 189-190. 
os alunos em comunidades de trabalho». ${ }^{8}$ Em contrapartida, «nas escolas das cidades se deveriam ter em conta as actividades características do agregado urbano; e na orla do mar as operações da pesca». ${ }^{9}$ De modo específico, António Sérgio argumentava que, nas escolas rurais, «a base do processo de instrução primária seria o trabalho no horto escolar, sendo inconveniente a simples difusão da arte da leitura». ${ }^{10}$ Retomava assim, de modo actualizado, os argumentos que havia sustentado cerca de quarenta anos antes e concluía que a formação profissional deveria ser introduzida no ensino de continuação, ou no ensino primário superior, pois que este grau de ensino deveria também assegurar a educação geral.

Nos textos republicanos, a temática da Escola Única surge frequentemente associada à educação popular, estando em questão a compatibilidade entre uma alfabetização comum e uma diferenciação escolar. A educação popular reportava ao imediatismo e ao utilitarismo das noções adquiridas. No âmbito da Seara Nova, tomando como representativo o depoimento de Ferreira de Macedo, era esperado que a educação popular assegurasse «ao indivíduo toda a soma de elementos necessários para que ele form[ass]e de si, da sociedade e do universo, a concepção mais perfeita que comporte a civilização contemporânea, a personalidade do indivíduo e o seu meio». ${ }^{11}$ Com objectivo de promover a alfabetização, atingindo populações que não dispunham de escola, os diferentes governos republicanos socorreram-se do Movimento das Escolas Móveis.

Conforme comprova José António Afonso, a República reiterou a diversidade entre os mundos urbano e rural, mas modelou a oferta escolar. Houve circunstâncias, a partir de 1918, em que a oficialização do Movimento das Escolas Móveis correspondeu a um ensino alternativo para o mundo rural. ${ }^{12}$ Conclui José António Afonso que o fomento da alfabetização, através desta modalidade de oferta escolar, não (pre)determinava uma escola reduzida ou menor para o mundo rural. A multiplicação des-

\footnotetext{
${ }^{8}$ Sérgio, Obras Completas, 255.

${ }^{9}$ Sérgio, Obras Completas, 255.

${ }^{10}$ Sérgio, Obras Completas, 275

${ }^{11}$ En Mário Sottomayor Cardia (org., prefácio e notas), Seara Nova. Antologia: pela Reforma da República (1) 1921-1926 (Lisboa: Seara Nova, 1971), 343.

${ }^{12}$ José António Afonso, Escolas Rurais na 1. ${ }^{a}$ República Portuguesa (1910-1926): discursos e representações sobre a periferia (Santo Tirso: Whitebooks, 2016).
} 
ta oferta escolar estava também associada aos Professores Livres. A modalidade de Escola Móvel foi frequente no ensino agrícola e profissional.

Como foi já referido, a Escola Única era o modelo consignado na Proposta de lei sobre a reorganização da educação nacional, também conhecida como Projecto Camoesas, apresentado no Parlamento em 1923. Este projecto, que não chegou a ser aprovado no Parlamento, tinha entretanto merecido aprovação no Congresso da União do Professorado Primário, realizado em Leiria, em Agosto daquele mesmo ano. Para a União do Professorado Primário, a Escola Única garantiria o direito à educação, respeitando as aptidões e os méritos de cada um, e asseguraria uma orientação profissional conforme às respectivas capacidades. ${ }^{13}$

\section{ALFABETIZAÇÃO E ESCOLARIZAÇÃO}

Na primeira metade do século xx, Portugal mantinha-se um país essencialmente rural e o combate ao analfabetismo frequentemente confundiu ruralismo com arcaísmo e menoridade cívica. Esta polémica, com origem e repercussões na escolarização das populações rurais, surgia, em regra, associada à polémica da Escola Única. Os núcleos urbanos estavam, de uma forma geral, servidos de escolas elementares e, em alguns casos, complementares. A distinção entre urbano e rural acentuava-se na falta de oportunidade, na dificuldade de acesso, mas não necessariamente na desvalorização da formação escolar. Com efeito, também para os estratos da população mais empobrecidos, mesmo que urbanos, e para uma parte significativa das populações rurais, o saber ler, escrever e contar, quer obtido de modo informal quer através da frequência escolar, não se traduzia necessariamente numa melhoria de vida.

O escritor Aquilino Ribeiro, conhecedor da realidade e da mentalidade dos "rústicos», foi partidário incansável da cultura e do progresso como meios de humanização. Interviera, numa contenda de ideias, em benefício da alfabetização e das virtualidades antropológicas e sociais da aculturação escrita. Fizera-o, reagindo ao editorial, de 9 de Janeiro de 1927, de $O$ Século. Nesse editorial, era reconhecido que «a vaga de analfabetismo que sufoca a sociedade portuguesa é intolerável. Constitui

${ }^{13}$ Cf. Áurea Adão, O Estatuto Sócio-Profissional do Professor Primário em Portugal (1901-1951) (Oeiras: Fundação Calouste Gulbenkian/ Instituto Gulbenkian de Ciência, 1984), 57. 
para este país uma vergonha sem nome» e, apesar dos esforços da República, "a situação de Portugal, no campo do ensino primário, é mais que humilhante, porque chega a ser vexatória». Aproveitando o ensejo, Aquilino Ribeiro publicou, no editorial de 10 de Janeiro do mesmo jornal, um artigo polémico que intitulou «Do absurdo de criar escolas». Nesse artigo, procurou demonstrar as anacronias do processo de desenvolvimento histórico de inspiração exógena, contrapondo os mundos rural e urbano. Relativamente ao primeiro, afirmou:

Todos nós, que nos criámos hábitos de civilizados, nos lastimamos a justo título das estradas que não são mais que ravinas, quando deviam ser alcatroadas, das escolas que não são suficientemente sumptuosas para ensinar os nossos filhos a ser gente, de todo esse pseudo-progresso bunda, reles, caótico, com que andamos a presumir europeus. [Mas] A aldeia portuguesa —o Norte, salvo a mancha das cidades e das vilas parasitárias- é isto, um conglomerado triste, selvagem, paupérrimo, que ofende toda a criatura de bem, que tenha o sentimento de solidariedade, já não digo humana, mas de raça. ${ }^{14}$

Ressalvava Aquilino Ribeiro que a causa desta situação era atribuída à falta de instrução. No entanto, este escritor —ele que, nas suas obras, glosou a sabedoria do mundo rural e recriou os mais profundos traços de carácter, virtude e honra que embelezavam a alma dos rústicos- advertiu que «a escola, por si só não resolve o problema do analfabetismo». Antes a questão deveria ser colocada na utilidade dessa aprendizagem. Desafiando o leitor, interrogava-se: «Para quê aprender a ler e a escrever naqueles lugares onde não há necessidade de ler e escrever?» $\mathrm{E}$ antes que a resposta surgisse ambígua, Aquilino Ribeiro empenhava a sua autoridade de humanista e voz do progresso afirmando:

No dia em que saber ler e escrever lhe seja tão útil como saber governar o arado, plantar feijões, ou até jogar o pau, nesse dia as escolas, as más anti-higiénicas e lôbregas escolas de Portugal abarrotarão de estudantes. Essa utilidade, é intuitivo, só pode obter-se mercê de medidas gerais de fomento, estradas, camin-

\footnotetext{
${ }^{14}$ O Século, 10 de Janeiro de 1927.
} 
hos-de-ferro, indústrias e mais aquisições da vida moderna, coisas estas, com o alfabeto, confluentes e conexas dum só progresso. ${ }^{15}$

De facto, no combate pela extinção do analfabetismo, o pretexto de que as causas do analfabetismo eram atribuídas à inexistência de escolas tornou frequente a confusão entre aculturação escrita e escolarização. Assim, no oposto do combate pelo fomento escolar que assegurasse o nível elementar de alfabetização, com sentido humanista e integrador da aculturação escrita (causa que mereceu o empenho de alguns periódicos e a dedicação de vozes como Aquilino Ribeiro), estavam periódicos e correntes de opinião que defendiam a preservação do arcaísmo e do isolacionismo rurais, como reserva moral e de nacionalismo. Para estes, a escola era interpretada como meio de fuga, pelo que não apenas se opunham à escola única, quanto sustentavam uma alfabetização que mantivesse o ruralismo como reserva moral.

\section{A ESCOLA NO MUNDO RURAL}

Como referido, as Escolas Móveis contribuíram para a ampliação de alfabetização quer dos adultos quer das próprias crianças em idade escolar, ainda que delas tenham beneficiado sobretudo os núcleos urbanizados e as sedes de concelho. Foram extintas pelo Decreto n. ${ }^{\circ} 18819$ de 5 de Setembro de 1930, passando a ser autorizada a criação de escolas temporárias, 'escolas incompletas', nas povoações rurais que tivessem, no mínimo, 30 crianças em idade escolar. Para que estas escolas funcionassem, bastaria que a leccionação fosse assegurada por uma pessoa que «possu[ísse] a necessária idoneidade moral e intelectual». Em 1931, estas escolas foram convertidas em Postos de Ensino, continuando a assegurar o 1. ${ }^{\circ}$ grau escolar ( 3 anos). A escola regimentalizada do Estado Novo foi sendo acomodada ao destino pátrio e reduzida a um minimum sociocultural. A ideia de reserva do mundo rural foi alimentada por diversos meios, mas não foi determinante.

A controvérsia em torno da Escola Única foi prolongada pela década de 30. Como negação e em contraponto à Escola Única do Trabalho defendida por António Sérgio e que pressupunha adaptações regionais

${ }^{15}$ O Século, 10 de Janeiro de 1927. 
alguns sectores conservadores lançaram a ideia de escola regional, como mais favorável no combate ao analfabetismo e à preservação da portugalidade. Neste quadro, em o jornal $A \mathrm{Voz}$, Manuel Múrias, que foi professor da Escola Normal Primária de Lisboa, defendeu a escola regional, correspondendo às características e às necessidades de cada região. ${ }^{16}$ Também Marcelo Caetano, que veio a ser Comissário Nacional da Mocidade Portuguesa, Ministro e Primeiro-ministro, sucedendo a Salazar, defendia, por contraponto à Escola Única, uma escola que assegurasse o direito das famílias. ${ }^{17}$

Datam do ano de 1933 um pequeno tratado sobre a organização da Escola Única, da autoria de Mário de Oliveira, ${ }^{18}$ e a publicação de uma conferência proferida, em Aveiro, por Álvaro Sampaio. ${ }^{19} \mathrm{Na}$ conferência «A Escola Única», proferida em 1935 na Sociedade de Estudos Pedagógicos, Bento de Jesus Caraça (destacado intelectual e cientista, Presidente do Conselho Administrativo da Universidade Popular Portuguesa), argumentando com base na psicologia, na pedagogia científica, na democracia e na salvaguarda das capacidades de cada um, defendeu de modo intransigente a Escola Única, pois que

a natureza humana é una e todo o ser humano é, por consequência, portador dos mesmos direitos; a todos deve, portanto, ser proporcionada a completa aquisição dos conhecimentos que lhe permitem viver dignamente a vida, conforme as suas capacidades - uma só condição, uma só dignidade, uma só escola. ${ }^{20}$

Admite Fernando Rosas que «não há, talvez, nada mais absurdamente demagógico no Portugal salazarista dos anos 30 do que o discurso ideológico, conservador, e agrarista sobre o mundo rural e a vida campone-

${ }^{16}$ Cf. José Salvado Sampaio, O Ensino primário 1911-1969. Contribuição Monográfica, volume II, 2. ${ }^{\circ}$ período-1926-1955 (Lisboa: Instituto Gulbenkian de Ciência/ Centro de Investigação Pedagógica, 1976), 21.

${ }^{17}$ Cf. Casimiro Manuel Martins Amado, O Debate acerca da Escola Única, na Imprensa Portuguesa (Évora: Universidade de Évora, 1991), 104.

${ }^{18}$ Cf. Mário de Oliveira, A Escola Única. Uma ideia pedagógico-social (Lisboa: Casa Editora Papelaria Fernandes, 1933).

19 Álvaro Sampaio, A Escola Única (Aveiro: Gráfica Aveirense, 1933).

${ }^{20}$ Bento de Jesus Caraça, Conferências e outros escritos, 2. ${ }^{a}$ edição (Lisboa: Tipografia António Coelho Dias, 1978), 105. 
sa». ${ }^{21}$ Era no mundo rural que as taxas de analfabetismo e a mortalidade infantil, associadas à pobreza e às más condições de higiene e alojamento, se acentuavam. O Mundo Rural era no entanto motivo de controvérsia. Se em algumas circunstâncias foi aglutinado, noutras foi objecto de reconhecimento da diferença, quer de região para região quer em face do mundo urbano. O Estado Novo, ao adoptar uma doutrina unitária e um regime corporativo, visou resolver a controvérsia. O ruralismo deveria permanecer nas economias regionais e na complementaridade orgânica. A Escola era unitária, mas o Professor, para além de ensinar, deveria prosseguir a tarefa moralizadora e morigeradora das populações rurais. Também era esperado que levasse alguma informação científica e técnica às populações. Partindo de uma análise dos manuais escolares, João Formosinho conclui que a mentalidade rural foi intensificada. ${ }^{22}$

O periódico Escola Portuguesa, publicado semanalmente entre 1934 e 1958 e mensalmente entre 1958 e 1974, da responsabilidade da Direcção Geral do Ensino Primário e considerado Boletim do Ensino Primário Oficial, nos termos do Decreto-lei n. ${ }^{\circ} 22369$, de 30 Março de 1933, prosseguiu uma via de não diferenciação para o mundo rural. Todavia, ficou povoado de estudos, proclamações, noticioso onde ressaltava o contraste entre aldeia e vila/cidade, entre rural e urbano. Ao longo da publicação, o rural foi frequentemente objecto e referência e pode observar-se uma sistemática focalizada no rural.

As Casas do Povo eram os locais onde os Professores deveriam prosseguir a missão civilizadora, como ressalta do depoimento de Alberto Eugénio Vaz Pires, professor da Escola do Magistério primário de Bragança, publicado na Escola Portuguesa n. ${ }^{\circ}$ 782, de 20-10-1949: «O professor tem na Casa do Povo a sua 2. ${ }^{\mathrm{a}}$ tribuna, o $2{ }^{\circ}$ baluarte de que pode e deve servir-se para espalhar a luz da civilização. $\mathrm{O}$ amor da Pátria, o culto do bem, as ideias progressivas». ${ }^{23}$

${ }^{21}$ Fernando Rosas, «O Estado Novo (1926-1974)» en História de Portugal (Sétimo volume), dir. José Mattoso (Lisboa: Círculo de Leitores, 1994), 53.

22 João Formosinho, Educating for Passivity - a study of portuguese education (1926-1968), Ph.D. thesis, University pf London [policopiado], 124-125.

${ }^{23}$ Apud Lília Alexandra Xavier Afonso Guedes, Escola Portuguesa (1934-1957). Sobre a Política Educativa do Estado Novo (Braga: Universidade do Minho/ Instituto de Educação, 1998), 108. 
Seria esperado que o professor fosse conselheiro, recebesse as autoridades quando de visita às aldeias, facultasse cuidados de vacinação, combate a infecções, resolução de pequenos acidentes. Frequentes vezes, o professor foi comparado ao agricultor, no ciclo de preparação da terra para a sementeira, na sementeira, no cuidado para a germinação e a frutificação, na colheita de fruto ou de resultados.

\section{MODELO ESCOLAR E ESCOLA ÚNICA}

No quadro internacional, a Escola Única era objecto de estudos histórico-pedagógicos com teor apologético. Nesse sentido, merece referência a obra de Ducos Hippolyte, Qual a razão da Escola Única, obra traduzida para português em 1933, na qual o autor proclamava: «a Escola única tem por fim a cultura humana de todas as crianças de França». ${ }^{24} \mathrm{Em}$ 1935, fora traduzida para português a obra A Revolução do Ensino pela 'Escola Única', da autoria de Pierre Flottes, com argumento de que «A Escola única, por muito diversa que se faça, produzirá, como consequência dos seus princípios, muitos diplomados». ${ }^{25}$ Como referido, tal opinião não era todavia sufragada de modo uniforme no contexto das novas perspectivas pedagógicas e democráticas, que propugnavam por uma acção educativa contextualizada e diversificada.

A afirmação do Estado Novo em Portugal foi acompanhada pelo fomento agrícola, através de políticas de colonização e fixação rural, e através de campanhas como a Campanha do Trigo. A intensificação do aproveitamento agrícola levou ao limite do solo arável. Dando consequência ao fomento agrícola e à ruralização, na reorganização das estruturas administrativas do Estado Novo, a Lei n. ${ }^{\circ}$ 1918, de 27 de Maio de 1935, continha as Bases do Ensino Rural. Tal ensino era destinado a transmitir noções gerais de agricultura e deveria variar de região para região. A lei, que não chegou a ser regulada, retomava um debate que vinha dos anos anteriores: o da escola regional.

No n. 327 da Escola Portuguesa, datado de 30 de Janeiro de 1941, vinha transcrita uma circular da Direcção-Geral do Ensino Primário, em

\footnotetext{
${ }^{24}$ Hippolyte Ducos, Qual a razão da Escola Única (Porto: Tipografia Civilização, 1933), 174.

${ }^{25}$ Pierre Flottes, A Revolução do Ensino pela «Escola Única» (Porto: Editora Livraria Escolar Progredior, 1935), 207.
} 
que era considerado pernicioso «o errado conceito, que nos meios rurais se formou, de que só nos centros citadinos se encontra o bem-estar, como o é a fuga para estes dos elementos necessários à prosperidade das terras em que nasceram». De acordo com o discurso oficial, os aldeãos tomavam a escola como meio de libertação, pois que:

a caneta era para eles a nova enxada, que não caleja as mãos nem lança terra para as costas e dá mais e melhor que comer. Se a escola coopera nestas loucas aspirações paternas, torna-se elemento prejudicial ao meio por alimentar o vício do urbanismo, rarefazendo de braços úteis a terra, que, sem eles, empobrece. ${ }^{26}$

A reserva moral e de regime com que foi contemplado o mundo rural correspondia a uma incapacidade do país em regenerar-se e modernizarse. A extensão colonial surgia como prolongamento do regime corporativo assente numa forte hierarquia social, contraponto à Europa e ao Ocidente escolarizado, culto, tecnológico, urbano e enriquecido.

No âmbito da Campanha Nacional de Educação de Adultos, a que já se fez referência, foi exarada uma determinação por parte do Subsecretário de Estado da Educação Nacional, Henrique Veiga de Macedo, nos seguintes termos:

1. A Direcção-Geral do Ensino Primário, os directores dos distritos escolares e os inspectores deverão redobrar de esforços para que a escola rural se não desligue do meio em que actua, antes se integre nele, compreendendo-o e estudando-o, de modo que seja possível provocar nos alunos marcado interesse pelos trabalhos agrícolas e amor consciente pela vida dos campos. ${ }^{27}$

Entre outros aspectos, tal orientação visava impedir que o combate ao analfabetismo favorecesse a fuga para as cidades. Junto de cada escola deveria funcionar uma horta escolar.

\footnotetext{
${ }^{26}$ Apud Sampaio, O Ensino Primário 1911-1969, 48-49.

${ }^{27}$ En Plano de Educação Popular VI. IV Reunião Anual dos Funcionários Superiores do Ensino Primário. Directivas dadas por Sua Excelência o Subsecretário de Estado da Educação Nacional (Lisboa: Campanha Nacional de Educação de Adultos, 1954), 196-197.
} 
Enfim, sistematizando o que tem vindo a ser constatado, conclui-se que, em Portugal, na viragem de Oitocentos, a agricultura absorvia $60 \%$ da população e havia 40\% de analfabetos. Até meados do século XX, os índices de ruralidade em termos demográficos, económicos e de desenvolvimento eram os mais acentuados. Na década de 60, prosseguindo a tendência iniciada ainda na década anterior, «a economia portuguesa registou um crescimento superior à média do crescimento das economias dos países industrializados da Europa». ${ }^{28}$ No entanto, em todo este longo tempo, não houve uma resposta escolar qualitativamente diferenciada para os universos urbano e rural.

A escola estabeleceu com a sociedade uma relação de exogenia. No quadro do Oitocentismo e do Republicanismo, o rural foi representado como arcaico, subdesenvolvido e de inevitável transformação. A escola dava curso a uma vulgata informativa de referente erudito, que incorporava uma pragmática urbana (configurados numa oficialização letrada) pouco facilitadora dos mecanismos de acesso, remediação, significação. Com o Estado Novo, a indeterminação face ao destino do rural reflectiu-se na implementação de uma escolarização minimalista e assim mesmo de orientação externa.

A historiografia da educação tem aqui algum contributo. Diferentes aspectos estão subjacentes à conveniência de equacionar uma relação escola-sociedade que vise ilustrar e dar a conhecer como a Escola Única portuguesa foi frequentemente objecto de contestação e de proposta de mudança. A acção e o produto escolar junto do mundo e da sociedade rural se não foram específicos também não foram uniformes. A história do ensino primário é central à Modernização ocidental e, por consequência, à modernização portuguesa, cuja evolução decorreu com assinaláveis variações na socialização da escrita e na progressão curricular, de segmento escolar para segmento escolar. Tais variações não permitem contudo iludir a manutenção de uma continuidade e de uma regularidade. Por outro lado, não deixam iludir ou despir de sentido a constatação de que convergem sobre a ruralidade e, por vezes, com a mesma perspectiva, olhares de diferentes disciplinas.

Poder-se-á perguntar se tais convergências resultam de transversalidades de uma mesma interpretação ou se, apesar da variação, não fazem

\footnotetext{
${ }^{28}$ Pedro Lains, Os progressos do Atraso. Uma Nova História Económica de Portugal, 1842-1992 (Lisboa: Imprensa de Ciências Sociais, 2003), 179.
} 
parte de conceptualização comum. De idêntico modo, é possível atender a uma continuidade conceptual ou orgânica de período histórico para período histórico. Desta continuidade ressalta uma segregação ou mesmo a ocultação do rural, subsumido no ideário e no currículo oficioso da Escola Única.

Uma leitura sistemática e crítica dos exemplares da revista Escola Portuguesa publicados no quinquénio de 1934 a 1939, período que corresponde à institucionalização do Estado Novo, permite comprovar que o rural era assunto de abordagem frequente, ainda que apresentado de forma indirecta. Uma dessas referências indirectas era a contraposição ao mundo urbano, apontado como perigoso e imoral. A análise da Escola Portuguesa permite de igual modo inferir que, pelo estatuto de periódico oficioso destinado a informar e normalizar, era aos profissionais espalhados pelo mundo rural que, verdadeiramente, se destinava esta revista.

Partindo da história da educação, observa-se que houve em torno da escolarização do rural uma diversidade de perspectivas, dependendo dos níveis de ensino e dos modos de descrever e apresentar o mundo e a realidade rural no plano curricular. A diversidade reporta também à variação de olhares, em função das distintas perspectivas pedagógicas e científicas. Da alfabetização até às classes escolares avançadas, o modo de incorporação variou: descrição, comparação, modelo. No plano disciplinar, é possível inventariar estudos e investigadores que tomaram em atenção a especificidade do rural, gerando uma construção semântica própria, ainda que nem sempre inteiramente distinta da do mundo urbano. Há estudos e investigadores que, aplicando marcos conceptuais gerais e fazendo uso de instrumentos analíticos comuns, demonstraram e ilustraram a existência de características típicas do mundo rural.

O modelo escolar foi uniforme, mas a historiografia não é uníssona sobre o rural. Também o mundo rural não foi uniforme, nem de conjuntura para conjuntura, nem no âmbito de uma mesma conjuntura. No plano curricular, pode aventar-se uma tónica geral: os textos, os tópicos e os programas escolares tenderam a representar o rural como tradição e mundo a descobrir. O processo escolar incluiu descrições e visitas de estudo, que tanto acentuam o contraste com a realidade urbana quanto caracterizam o rural como um tempo e um modo de vida saudável, idílico. 


\section{O MUNDO RURAL: ESCOLARIZAÇÃO REDUZIDA}

A uniformidade do modelo escolar comportou ajustamentos, de que resultou porventura uma escolarização menos exigente e mais reduzida. Com o Estado Novo, a ampliação escolar através da multiplicação de Postos Escolares foi apresentada como medida económica e tendente a fazer crescer rapidamente o número de alfabetizados. $\mathrm{O}$ mais controverso, porém, foi o processo de recrutamento dos docentes, que, sem uma formação prévia (curricular ou pedagógica), eram inseridos na instituição escolar. O recrutamento dos Regentes era feito através da aprovação em exame de habilitação correspondente à Instrução Elementar, o que nem assegurava que tivessem tido um percurso escolar, nem que soubessem leccionar. O resultado da acção docente dos Regentes corresponderia a uma alfabetização elementar, a qual, para a generalidade dos alunos, se tornava inconsequente na prossecução de estudos.

Pelo Relatório que a inspectora Áurea Judite do Amaral enviou ao Director Geral do Ensino Primário, relativo aos Exames de Aptidão para Regentes dos Postos de Ensino realizados em Viana do Castelo (entre 25 de Agosto e 1 de Setembro de 1936), fica-se informado que concorreram 54 candidatos, sendo 27 do género masculino e 27 do género feminino. Foram aprovados 22 candidatos, sendo 15 do género masculino e 7 do feminino. Reprovaram cerca de 55\% dos candidatos. Procurando uma interpretação para aqueles resultados, a Inspectora não atenta propriamente na percentagem global de reprovações, mas na discrepância entre o género masculino e o feminino, que atribui ao facto de que, «na maior parte, os candidatos pertenceriam ao meio rural, onde a cultura das raparigas é, por via de regra, mais descurada. Aí deve estar a diferença; os candidatos do sexo masculino tinham maior cultura». ${ }^{29}$ Em idênticas circunstâncias, o Inspector que presidiu aos exames no distrito de Bragança relatou que foram admitidos à Prova 36 candidatos ( 5 do género masculino e 31 do feminino), tendo sido aprovados apenas $28 \%$. Já no ano de 1935, os relatórios dos inspectores aos exames realizados em Faro davam nota da insuficiente preparação dos candidatos. Foram admitidos 18 dos 44 candidatos a provas e as debilidades eram sobretudo acentuadas na língua portuguesa. Como referido, parte desses candidatos eram oriundos das regiões rurais, pelo que a endogenia do mundo rural não seria auto-suficiente para a regeneração escolar. $\mathrm{O}$ en-

\footnotetext{
${ }^{29}$ Escola Portuguesa, Ano III, n. ${ }^{\circ} 105,22 / 10 / 1936$.
} 
sino escolar incide sobre a norma linguística e era, sobretudo, em língua materna que se acentuavam as falhas dos examinados.

Na Lei n. ${ }^{\circ}$ 1969, de 20 de Maio de 1938, que continha as bases da Reforma do Ensino Primário, ficava reiterado que os Postos Escolares não eram Escolas. Ficava aberta a possibilidade de, no final de cinco anos de trabalho, os Regentes poderem requerer Exame de Estado, no qual seria tomada em atenção a experiência pedagógica e a formação entretanto obtida. Como princípio geral ficava estipulado que a habilitação de professores e regentes «terá sentido imperial, corporativo e predominantemente rural, abrangerá aprendizagem dum ofício e, na medida do possível, a prática da psicotecnia, para se descobrir a aptidão natural dos alunos». ${ }^{30}$

Criados pelo Decreto n. ${ }^{\circ} 20.604$, de 09 de Dezembro de 1931, os Postos de Ensino foram convertidos em Postos Escolares pelo Decreto n. ${ }^{\circ} 27279$, de 24 de Novembro de 1936. A expansão da rede escolar através da modalidade de Postos Escolares foi intensa. Na década de 40 representavam $33 \%$ do total de escolas oficiais. ${ }^{31}$ Os edifícios escolares de raiz, construídos no âmbito do Plano dos Centenários, obedecendo muito embora a um padrão arquitetónico, incorporavam uma feição regional no tipo de materiais e na disposição de alguns elementos decorativos.

Confrontando os relatórios das inspecções de 1948-49 e 1958-59, António Nóvoa inferiu algumas melhorias, nomeadamente no estado dos edifícios escolares, mas ressalva que os inspectores continuavam a fazer apreciações bastantes críticas em relação ao ensino primário nos meios rurais. Entre outros aspectos, designadamente a precaridade dos materiais didácticos e o pouco empenho das comunidades rurais na escola, os inspectores ressaltavam a ausência de inovação e de modernização pedagógica, por parte dos professores. ${ }^{32}$

A ruralidade estava presente na formação de professores e no ideário escolar mas de forma mitigada, como conclui Sandra Lima, analisando

\footnotetext{
${ }^{30}$ Apud Sampaio, O Ensino primário 1911-1969, 69.

${ }^{31}$ Cf. Áurea Adão, «A Escola em meio Rural no Portugal dos primeiros Anos do Estado Novo. A formação dos seus professores», en Educação Rural em Perspectiva Internacional. Instituições, Práticas e Formação do Professor, org. Flávia Obino Corrêa Werle (Ijuí, RS, Brasil: Ed. Unijuí), 280.

32 António Nóvoa, «A “Educação Nacional” », 482-483.
} 
os Editoriais dos primeiros cinco anos da Revista Escola Portuguesa. ${ }^{33}$ A apologia do rural e a sua lenta evolução, ainda que povoada por pólos urbanizados cada vez mais notórios na paisagem, prolongou-se no imediato Pós-II Guerra, mas tornou-se insustentável a partir de final dos anos 50. No entanto, de acordo com a classificação adoptada no Recenseamento Geral da População, em 1960, a grande maioria da população portuguesa era rural. Nessa classificação, era tomado como centro urbano «a capital de distrito e a localidade qualquer que fosse a sua categoria legal (cidade, vila, etc.) que, na área urbana, demarcada pela Câmara Municipal respectiva, contasse 10000 ou mais habitantes». ${ }^{34}$

A uniformidade curricular foi também sustentada pela prática do Livro Único e pela correspondência escolar. ${ }^{35}$ A escolarização elementar e a alfabetização de adultos haviam sido objecto de políticas específicas entre finais da década de 40 e o primeiro lustro da década de 50, de que resultaram uma aproximação acelerada ao cumprimento da escolaridade obrigatória por parte dos grupos etários infanto-juvenis e uma notória melhoria de certificação escolar de adultos, reduzindo significativamente as taxas de analfabetismo. Foram políticas orientadas para a (re)construção e a participação cívica do Estado Corporativo, modelo desenvolvimentista sujeito a grande controvérsia, sobretudo por parte dos partidários da grande indústria e da agro-indústria.

Também neste sentido foi significativa a polémica gerada, nos anos finais da década de 60, em torno do Estatuto Jurídico das Corporações, lançado pelo Ministério das Corporações como instrumento de revitalização e de regulação do Estado Corporativo. As Ordens Profissionais, nomeadamente a Ordem dos Médicos e a Ordem dos Engenheiros, com Estatutos que salvaguardavam a especificidade —desde as condições de admissão até ao exercício profissional_- contestaram aquele Estatuto. Também o estatuto dos trabalhadores rurais foi objecto de controvérsia.

\footnotetext{
${ }^{33}$ Cf. Sandra Cristina Fagundes de Lima, «O Não dito: História da Escola primária Rural nas Páginas da Revista Escola Portuguesa (Portugal, 1934-1939)», Educação e Filosofia, Uberlândia, 27, n. especial (2013), 109-142.

${ }^{34}$ INE, Recenseamento Geral da População, Volume II (Lisboa: INE, 1960), VII.

${ }^{35}$ Cf. Maria Isabel Aleixo \& Maria do Céu Alves, «A Cultura Escolar e a Formação dos Mestres de Ensino Primário na Escola Rural, através da Produção Escrita dos Alunos, de 1956 a 1960», en Educação Rural em Perspectiva Internacional. Instituições, Práticas e Formação do Professor, org. Flávia Obino Corrêa Werle (Ijuí, RS, Brasil: Ed. Unijuí, 2007), 335-369.
} 
Entre 1950 e 1974, a população empregada no sector primário passou de $50 \%$ para $34 \%$ da população portuguesa activa. No mesmo período, a população dedicada ao sector secundário subia de $24 \%$ para $33 \%$. A década de 60 abriu à mecanização e à modernização. Abriu, de igual modo, a experiências pedagógicas no âmbito da escolaridade obrigatória, seja para reformulação da uniformidade escolar, seja como ensino de continuidade. Estas experiências pedagógicas intentavam congregar um tronco comum com uma progressiva abertura vocacional e profissional. Nos termos do Decreto-Lei n. ${ }^{\circ} 45810$, de 9 de Julho de 1964, a Escolaridade Obrigatória foi ampliada para 6 anos. No entanto, o prolongamento da escolarização para o mundo rural foi no essencial obtido através do Ciclo Complementar da Instrução Primária (5. ${ }^{\mathrm{a}}$ e $6{ }^{\mathrm{a}}$ Classes), como aliás reconheceu o então Ministro da Educação Nacional, Inocêncio Galvão Teles. ${ }^{36}$

\section{EDUCAÇÃO RURAL NO MUNDO}

Ao longo da primeira metade do século xx, o mundo rural evoluiu de forma diversa de país para país e de continente para continente. Os países mais desenvolvidos eram os que apresentavam uma indústria, uma urbanização e um comércio desenvolvidos, mas eram também aqueles em que o mundo rural tinha vindo a perder influência, transformando-se, de modo análogo, na qualidade de vida e no crescimento orientado para um mesmo progresso. A economia e o desenvolvimento caminhavam em paralelo. A generalidade dos países em vias de desenvolvimento emergiam de uma economia basicamente agrícola, e a ruralidade era progressivamente interpretada como sinónimo de pobreza e como conservadora das assimetrias sociais e das hegemonias internacionais. O rural, como realidade assimétrica endógena, contraponto do urbano e alternativa para o desenvolvimento, ou, por outro lado, como local de pobreza e êxodo das populações, era objecto de uma preocupação internacional acrescida, coordenada pela UNESCO. Para a UNESCO, a redução do analfabetismo era um indicador do progresso cultural. Portugal apresentava a mais baixa redução de analfabetismo da Europa entre 1900 e $1940 .{ }^{37}$

\footnotetext{
${ }^{36}$ Cf. Inocêncio Galvão Telles, Temas de Educação (Lisboa: Ministério da Educação Nacional, 1966), 175-202.

${ }^{37}$ Cf. Plano de Educação Popular XVI, Série A, N. ${ }^{\circ}$ 11, Na Segunda Fase do Plano de Educação Popular. Discursos proferidos por SS. Exas o Ministro e o Subsecretário de Estado da Educação Nacional, na reunião das Comissões Centrais e da Comissão Distrital de Lisboa da Campanha Nacional de Educação
} 
No ano de 1958, a UNESCO publicou o estudo Possibilités d'Accès à l'Éducation dans les Zones Rurales. ${ }^{38}$ Tratava-se do resultado do Inquérito dirigido pela Division des Recherches du Bureau International d'Éducation e a que haviam respondido 71 países. O questionário foi dirigido aos Ministérios de Instrução Pública e incidia sobre estabelecimentos escolares do ensino obrigatório, situados em zonas rurais. Estava organizado em seis secções, que configuram a escola como instituição educativa: administração escolar; organização escolar; planos de estudos, programas e métodos; pessoal docente; acção em benefício da igualdade de acesso à educação; diversos. No conjunto, eram doze quesitos, parte dos quais desdobrados em diversos itens. Do item administração consta a indagação sobre os critérios de delimitação entre o urbano e o rural.

As respostas contemplam, no essencial, o critério demográfico. $\mathrm{Na}$ Introdução àquele estudo, Roger Girod (membro da Division de Recherches du Bureau International d'Éducation) concluía: «tous les pays qui ont répondu à l'enquête s'efforcent de diminuer l'écart qui sépare les populations rurales des autres en matière d'éducation». A generalidade dos países aplicava os mesmos textos legislativos às populações rurais e às populações urbanas. Em alguns países, as actividades escolares eram orientadas nuns locais para actividades agrárias e noutros para a indústria em sentido amplo. Com base nos dados obtidos, os autores do comentário ao relatório aventavam a hipótese de que os países

dans lesquels tous les enfants normaux des zones rurales vont à l'école primaire et y restent autant d'années que ceux des villes doivent comprendre à peu près de tiers de la population mondiale totale et seulement une fraction bien moindre de le population rurale du globe. Il s'agit en effet des pays les plus industrialisés. ${ }^{39}$

Por contraponto, nos países que consideravam uma duração efectiva da escolaridade obrigatória menor que a urbana, os índices de frequência eram também mais reduzidos, podendo oscilar entre $80 \%$ e $50 \%$ o

de Adultos, em 3 de Dezembro de 1955 (Lisboa: Campanha Nacional de Educação de Adultos, 1955), 15.

${ }^{38}$ UNESCO, Possibilités d'Accès à l'Éducation dans les Zones Rurales (Paris/ Genève: Unesco/ Bureau International d'Éducation, 1958).

${ }^{39}$ UNESCO, Possibilités d'Accès à l'Éducation dans les Zones Rurales, 13. 
total de crianças das zonas rurais que não iam à escola. Roger Girod salientava o princípio geral de que a escolarização acompanhava o desenvolvimento económico e social dos diversos países e que eram os países mais industrializados que apresentavam uma escolarização universal.

No que reporta aos planos de estudo, a generalidade dos países mantinha os mesmos programas em todo o território, mas com adaptação ao meio — caso dos Estados Unidos da América, Suíça, Reino Unido, Países da América do Sul. Na União Soviética, eram consideradas as diferenças nos Abecedários e na orientação para a produção. No que se refere à remuneração, em muitos países, os docentes do mundo rural recebiam um reforço de salário. Havia países que sustentavam transportes escolares e apoios sociais às crianças com menos facilidade de acesso à escola, enquanto outros, nomeadamente os Estados Unidos da América e a Espanha, estavam a implementar sistemas de concentração dos alunos em centros escolares.

As autoridades portuguesas deixaram alguns quesitos sem resposta, talvez por não os considerarem ajustados. Àqueles a que responderam, designadamente o referente a diferenças quanto a organização escolar, responderam laconicamente "aucune différence»; 40 quanto aos planos escolares e ao pessoal docente, a mesma resposta lacónica: «pas de différence ${ }^{41} \mathrm{Em}$ modo de síntese, os organizadores da publicação registavam que o Ministério da Educação Nacional de Portugal «declare simplement que dans ce pays, il n'y a pas en principe de différence entre les écoles des zones urbaines et celles des zones rurales; l'obligation scolaire s'applique de la même façon dans toutes les régions». ${ }^{42}$

Assim portanto, um país que considerava como rural a maioria da população e que apresentava uma diversidade económica progressivamente mais reconhecida (entre o Portugal Rural, o Litoral e o Urbano) não reconhecia, porém, uma diferenciação escolar positiva em face das assimetrias entre o rural e o urbano. A confusão entre «escola única» e «escola portuguesa» continuava a impedir o ajustamento curricular. Do receio do "terceiro instruído», para fazermos uso da expressão tão cara

\footnotetext{
${ }^{40}$ UNESCO, Possibilités d'Accès à l'Éducation dans les Zones Rurales 15.

${ }^{41}$ UNESCO, Possibilités d'Accès à l'Éducation dans les Zones Rurales 20 e 24 .

${ }^{42}$ UNESCO, Possibilités d'Accès à l'Éducation dans les Zones Rurales 193.
} 
a pensamentos críticos como o de António Sérgio e o de Michel Serres, continuava a resultar afinal um «terceiro dominado».

Como referido, a acentuada melhoria dos índices de alfabetismo, por meados do século XX, resultou da intensificação da escolarização infantil a partir da segunda metade da década de 40 e do Plano de Educação Popular, que incluía a Campanha de Alfabetização de Adultos, lançada a partir de 1952. Estes movimentos, que congregavam o Ministério da Educação Nacional e o Ministério das Corporações, estavam orientados para a revigoração do Estado Corporativo, quer junto das fábricas quer junto dos trabalhadores rurais e dos pescadores. Pelo Decreto-Lei n. ${ }^{\circ}$ 40678, de 10 de Julho de 1956, o Ministério da Educação Nacional autorizava as Escolas de Serviço Social a criarem os seguintes cursos: a) Curso de Serviço Social; b) Curso Geral de Educação Familiar; c) Curso Normal de Educação Familiar (Art. ${ }^{\circ} 3$ ). ${ }^{43}$ Posteriormente, foram criados Cursos de Agentes de Educação Familiar Rural, nas Escolas D. Luiz de Castro, em Braga; Escola de Formação Social de Leiria; Escola de Formação Social de Lamego. Na criação destes cursos estava reflectida a influência da Organização Europeia de Cooperação Económica (OECE), criada em 16 de Abril de 1948, e de que Portugal era membro fundador. A questão do analfabetismo estava ligada ao combate à pobreza e ao fomento do desenvolvimento. A necessidade de uma melhoria geral da qualidade de alimentação da população portuguesa, com relevo para a melhoria da produção agrícola, fora assinalada pelo estudo Problema Alimentar Português, publicado pela Direcção-Geral dos Serviços Agrícolas (1950). ${ }^{44}$

\section{CONCLUSÃO}

A relação entre Escola Única e educação rural, designadamente em Portugal, reporta a comunalidades e contrastes que resultam dos quadros histórico-pedagógicos, mas também das indeterminações político-ideológicas, quer por parte dos regimes republicanos e democráticos quer por parte dos governos centralizados e totalitários, ditos Estado Novo. Não houve uniformidade, nem continuidade quanto à representação

${ }^{43}$ Diário do Governo n. ${ }^{\circ}$ 143, I Série, de 10 de Julho de 1956.

${ }^{44}$ António Sérgio, Obras Completas, 149. 
científico-pedagógica do rural ou quanto à inclusão do rural no currículo escolar. Se o caso português não é isolável, nem poderá ser tomado como exemplo, então a problemática é mais ampla e transversal. O que verdadeiramente estava em questão era o destino histórico do mundo rural e era a relação entre escola e mundo rural. A instituição-escola foi interpretada como exógena. O cumprimento escolar era um processo de elevação, cuja certificação era factor de mobilidade. O modelo de desenvolvimento histórico gerou um alinhamento e uma secundarização do rural face ao urbano; da agricultura face à indústria; da total substituição da economia de troca pela mercantilização.

A cultura rural serviu a Escola Activa, nos planos material e simbólico, possibilitando ensino de coisas, excursões escolares, manipulação e construção de artefactos educativos. Comportou uma profissionalização, mas a escola trazia subjacente um outro modelo desenvolvimentista. Com efeito, foi no âmbito da Escola Activa inspirada nos Centros de Interesse de Decroly que, como suporte para um ensino intuitivo, as Escolas de Magistério Primário e a Inspecção Escolar recomendavam que os professores tomassem em atenção a realidade local. Tal influência ressalta de alguns trabalhos dos alunos, nas décadas de 40 e 50, em Portugal, designadamente a correspondência escolar; mas a educação rural não foi parte do modelo escolar.

Pelo Inquérito da UNESCO, de meados do século, quando cerca de $30 \%$ da população mundial vivia em cidades, fica a saber-se que, para os países desenvolvidos, a escolarização básica estava adquirida e que a relação entre o mundo rural e o mundo urbano e mesmo entre a economia agrícola e a economia industrial e mercantil traduzia grandes desigualdades e assimetrias. No entanto, a urbanização tendia a acelerar, como veio a acontecer, pois que, na actualidade, mais de metade da população mundial vive em grandes centros urbano-industriais. A instituição-escola assegurava uma educação básica, no essencial comum, ajustando-se a nível didáctico e organizacional. As inter-relações entre as geografias rural e urbana, articuladas pela aculturação escrita e pela cultura escolar, eram de ordem cultural, administrativa, judicial, cívica.

A escolarização do rural não pôde deixar de acompanhar a escolarização urbana. As assimetrias acentuavam-se na razão inversa ao desen- 
volvimento. O ensino agrícola era de continuidade e matéria da educação secundária. O período compreendido entre 1950 e 1970 foi de excepcional crescimento na economia mundial, acelerado pela industrialização ${ }^{45}$. Do Inquérito da UNESCO ressaltam, enfim, a maturidade do institucional escolar e o significado da escola-instituição como meio e indicador de desenvolvimento. A escola era, desde então, uma causa, senão a causa da UNESCO. Educação, na polissemia do termo (aculturação, emancipação, promoção, participação), era sinónimo de desenvolvimento.

Em Portugal, não obstante a percentagem da população rural, observa-se que, no plano formal, houve uma quase-ignorância do rural como mundo humanizado, com cultura, economia e destino próprios. Uma aproximação sumária ao ideário da reforma escolar iniciada com a Ditadura Militar e prosseguida com o Estado Novo evidencia aspectos onde a ruralidade foi tomada como objectivo e linha de horizonte, seja como tradição e reserva moral, seja como impedimento do êxodo para as cidades. Da Ditadura Militar para o Estado Novo houve continuidade na ampliação da oferta escolar, através de estruturas escolares precárias que facultavam um minimum curricular. Os Postos de Ensino deram lugar a Postos Escolares, disseminadas pelo país rural. Os Postos Escolares, ainda que tenham sido também criados em populações peri-urbanas, eram pequenas unidades de ensino isoladas, multigraduadas, confiadas à figura do Regente Escolar. Asseguravam uma escolarização reduzida e só pontualmente transformativa do local. A escolarização, em pouco serviu a endogenia. Caminhou na direcção do urbano, do industrial, do terciário. Foi entre as populações rurais que as taxas de analfabetismo e o incumprimento escolar tardaram a desaparecer.

\section{Nota sobre o autor}

Justino Magalhães, Historiador da Educação, Professor Catedrático do Instituto de Educação da Universidade de Lisboa. Domínios de investigação e publicação: História da Educação e da Escolarização; História da Alfabetização; História do Livro Escolar; História das Instituições Educativas; História do Local e do Município Pedagógico.

\footnotetext{
${ }^{45}$ Cf. Chris Freeman e Francisco Louçã, Ciclos e Crises no Capitalismo Global. Das Revoluções Industriais à Revolução da Informação (Porto: Edições Afrontamento, 2003), 305.
} 


\section{REFERÊNCIAS}

AdÃo, Áurea. O Estatuto Sócio-Profissional do Professor Primário em Portugal (1901-1951). Oeiras: Fundação Calouste Gulbenkian/ Instituto Gulbenkian de Ciência, 1984.

- «A Escola em meio Rural no Portugal dos primeiros Anos do Estado Novo. A formação dos seus professores». In Educação Rural em Perspectiva Internacional. Instituições, Práticas e Formação do Professor, edited by organização de Flávia Obino Corrêa Werle, 269-293. Ijuí, RS, Brasil: Ed. Unijuí.

Afonso, José António. Escolas Rurais na 1. ${ }^{a}$ República portuguesa (1910-1926): Discursos e representações sobre a periferia. Santo Tirso: Whitebooks, 2016.

AleIXo, Maria Isabel y Maria Do CÉu Alves. «A Cultura Escolar e a Formação dos Mestres de Ensino Primário na Escola Rural, através da Produção Escrita dos Alunos, de 1956 a 1960». In Educação Rural em Perspectiva Internacional. Instituições, Práticas e Formação do Professor, edited by organização de Flávia Obino Corrêa Werle, 335-369. Ijuí, RS, Brasil: Ed. Unijuí, 2007.

Amado, Casimiro Manuel Martins. O Debate acerca da Escola Única, na Imprensa Portuguesa. Évora: Universidade de Évora, 1991.

Caraça, Bento de Jesus. Conferências e outros escritos, 2. a edição. Lisboa: Tipografia António Coelho Dias, 1978.

CARDIA, Mário Sottomayor. Seara Nova. Antologia: pela Reforma da República (1) 1921-1926. Lisboa: Seara Nova, 1971.

Ducos, Hippolyte. Qual a razão da Escola Única. Porto: Tipografia Civilização, 1933.

Flottes, Pierre. A Revolução do Ensino pela "Escola Única". Porto: Editora Livraria Escolar Progredior, 1935.

Formosinho, João. «Educating for Passivity - a study of portuguese education (1926-1968)». PhD diss., University of London [policopiado], London, s/d.

Freeman, Chris y Francisco Louçã. Ciclos e Crises no Capitalismo Global. Das Revoluções Industriais à Revolução da Informação. Porto: Edições Afrontamento, 2003.

Guedes, Lília Alexandra Xavier Afonso. Escola Portuguesa (1934-1957). Sobre a Política Educativa do Estado Novo. Braga: Universidade do Minho/ Instituto de Educação, 1998.

INE. Recenseamento Geral da População, Volume II. Lisboa: INE, 1960.

LaIns, Pedro. Os progressos do Atraso. Uma Nova História Económica de Portugal, 1842-1992. Lisboa: Imprensa de Ciências Sociais, 2003.

Lima, Sandra, Cristina Fagundes. «O Não dito: História da Escola primária Rural nas Páginas da Revista Escola Portuguesa (Portugal, 1934-1939)». Educação e Filosofia, Uberlândia, 27 n. especial (2013): 109-142. 
Magalhães, Justino. Da Cadeira ao Banco. Escola e Modernização (séculos XVIII-XX). Lisboa: Educa, 2010.

- «O Rural e a Escolarização em Portugal». Educação e Filosofia, Uberlândia, 27, número especial (2013): 63-73. Consultado el 10 de febrero de 2017.http:// dx.doi.org/10.14393/REVEDFIL.issn.0102-6801.v27nEspeciala2013-p63a74

Marques TeIXeIRa [Manuel Marques Teixeira de Oliveira]. Leonardo Coimbra e a Escola Única. Porto: Edições Marânus, 1961.

NóvoA, António. "A “Educação Nacional”». In Portugal e o Estado Novo (19301960), [Nova História de Portugal - vol. XII], edited by Fernando Rosas, 454519 y 538-542. Lisboa: Editorial Presença,1992.

OliveIra, Mário de. A Escola Única. Uma ideia pedagógico-social. Lisboa: Casa Editora Papelaria Fernandes, 1933.

Rosas, Fernando. «O Estado Novo (1926-1974)». In História de Portugal, edited by José Mattoso, Sétimo volume. Lisboa: Círculo de Leitores, 1994.

SAMPAIO, Álvaro. A Escola Única. Aveiro: Gráfica Aveirense, 1933.

SAmpaIo, José Salvado. O Ensino primário 1911-1969. Contribuição Monográfica, volume II, 2. ${ }^{\circ}$ período - 1926-1955. Lisboa: Instituto Gulbenkian de Ciência/ Centro de Investigação Pedagógica, 1976.

- O Ensino Primário 1911-1969. Contribuição Monográfica. Volume II (2. ${ }^{\circ}$ Período - 1926-1955). Lisboa: Instituto Gulbenkian de Ciência/ Centro de Investigação Pedagógica, 1976.

SÉrgio, António. Obras Completas. Democracia. Diálogos de Doutrina Democrática. Alocução aos Socialistas. Cartas do Terceiro Homem. Lisboa: Livraria Sá da Costa Editora, 1974.

Telles, Inocêncio Galvão. Temas de Educação. Lisboa: Ministério da Educação Nacional, 1966.

UNESCO. Possibilités d'Accès à l'Éducation dans les Zones Rurales. Paris/ Genève: Unesco/ Bureau International d'Éducation, 1958.

VVAA. Plano de Educação Popular VI. IV Reunião Anual dos Funcionários Superiores do Ensino Primário. Directivas dadas por Sua Excelência o Subsecretário de Estado da Educação Nacional. Lisboa: Campanha Nacional de Educação de Adultos, 1954.

VVAA. Plano de Educação Popular XVI, Série A, N. ${ }^{\circ} 11$, Na Segunda Fase do Plano de Educação Popular. Discursos proferidos por SS. Exas o Ministro e o Subsecretário de Estado da Educação Nacional, na reunião das Comissões Centrais e da Comissão Distrital de Lisboa da Campanha Nacional de Educação de Adultos, em 3 de Dezembro de 1955. Lisboa: Campanha Nacional de Educação de Adultos, 1955. 